\title{
Susceptibility of Triatoma infestans to deltamethrin in Rio Grande do Sul, Brazil
}

\author{
Ivan Vieira Sonoda ${ }^{1 /+}$, Grasiele Caldas D'Ávila Pessoa ${ }^{1}$, Mirko Rojas Cortez², \\ João Carlos Pinto Dias', Alvaro José Romanha', Liléia Diotaiuti'
}

'Laboratório de Triatomíneos e Epidemiologia da Doença de Chagas, Instituto de Pesquisas René Rachou-Fiocruz, Av. Augusto de Lima 1715, 30190-002 Belo Horizonte, MG, Brasil ²Programa Nacional de Chagas, Ministerio de Salud y Deportes, Bogotá, Bolivia

Strategies for controlling Chagas disease are based on spraying infested houses with pyrethroid insecticides. However, the intense use of these insecticides has promoted resistance of Triatoma infestans and, in Argentina, Bolivia and Southern Brazil, low levels of resistance have been reported. Due to the persistence of $\mathrm{T}$. infestans in the state of Rio Grande do Sul (RS), we evaluated the occurrence of deltamethrin resistance in four strains from different municipalities in comparison to two susceptible strains from Brazil and one resistant strain from Bolivia. The results indicated the absence of resistance in $\mathrm{T}$. infestans from $R S$.

Key words: Triatoma infestans - pyrethroid resistance - Chagas disease

Strategies for controlling Chagas disease are based principally on the interruption of vectorial transmission. In Brazil, the control programme reached its operational peak in the 1980s (Vinhaes \& Dias 2000). From 1986 onwards, its activities were reduced due to the rise in epidemics of dengue, although the programme continued to spray infested residences throughout the country. In 1991, as part of the Southern Cone Initiative and an effort of the Ministries of Health of Argentina, Brazil, Bolivia, Chile, Paraguay and Uruguay, the Chagas Disease Control Programme (PCDCH) began to prioritise areas where Triatoma infestans occurred, establishing epidemiological surveillance in those areas where vectorial transmission was already being controlled (Dias et al. 2002).

The efficacy of residual insecticides in combating triatomines was demonstrated for the first time in the late 1940s (Dias \& Pellegrino 1948) with applications of hexachlorobenzene (HCB). Once this compound became readily available, it was possible to establish large-scale control programmes. These were highly successful, and vectorial transmission of Chagas disease was reduced over wide geographical areas. However, the agricultural use of HCB was prohibited in the mid-1980s due to its high environmental toxicity, precluding further commercial production. Fortunately, by this time, the efficacy of several pyrethroids against triatomines had been proven, and these insecticides began to be used routinely by the PCDCH (Diotaiuti et al. 1994, Dias 2002).

\footnotetext{
Financial support: FAPEMIG, FIOCRUZ, Bayer CropScience

+Corresponding author: ivansonoda@hotmail.com

Received 23 November 2008

Accepted 15 April 2009
}

Few studies have been carried out on insecticide resistance in triatomines. The first report came from Venezuela in the 1970s, on areas where Rhodnius prolixus was regularly treated with HCB (Rocha \& Silva 1979). The first evidence of resistance to synthetic pyrethroids was obtained by the Centro de Investigaciones de Plagas e Insecticidas, in Buenos Aires, in the 1990s (Vassena et al. 2000). In this pioneer study, R. prolixus from Venezuela and $T$. infestans from the Brazilian state of Rio Grande do Sul (RS) were studied, and the authors found resistance ratio (RR) values characteristic of populations already possessing initial resistance. $R$. prolixus presented the highest values $(\mathrm{RR}=12.4$ for cypermethrin and 11.4 for deltamethrin) and $T$. infestans the lowest $(\mathrm{RR}=$ 7.0 for deltamethrin), although the precise origin of the latter specimens was not specified.

In this study, we investigated deltamethrin resistance in specimens of $T$. infestans from four different municipalities of north-eastern RS (Figure): Doutor Mau-

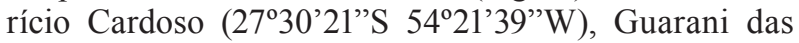

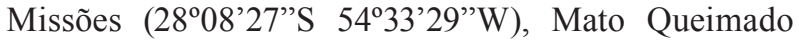

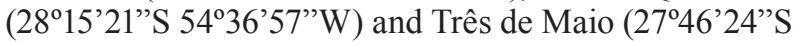
$54^{\circ} 14^{\prime} 24^{\prime \prime} \mathrm{W}$ ). These municipalities lie within an area that includes many residual $T$. infestans foci remaining after successive sprayings with pyrethroids (Dias 2002). It has not been determined whether the difficulty in eliminating $T$. infestans from this state is due to the operational difficulties of achieving insecticide coverage in the areas being treated (comprising ranches with very large, complex constructions) or to the fact that triatomines are truly resistant to insecticides. The following numbers of $T$. infestans specimens were obtained from each municipality: Doutor Maurício Cardoso (5 adults and 7 NV), Guarani das Missões (12 adults and 8 NV), Mato Queimado (11 adults and $17 \mathrm{NV})$ and Três de Maio (9 adults and $5 \mathrm{NV}$ ). All of these samples were reared in the laboratory and bioassays were performed with the second generation from these colonies. 


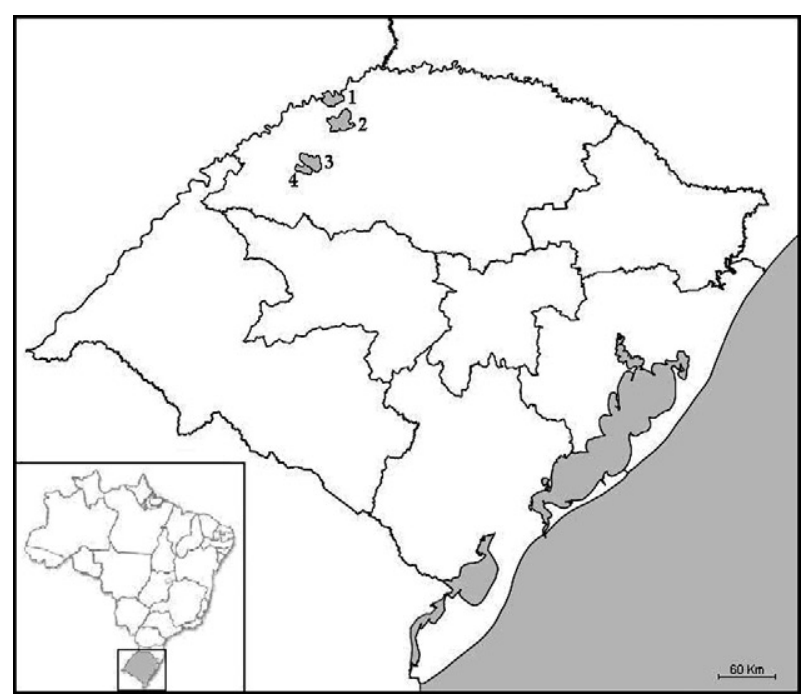

Map of the Brazilian state of Rio Grande do Sul showing localities from which Triatoma infestans specimens were obtained: 1: Doutor

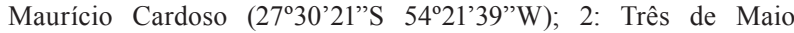

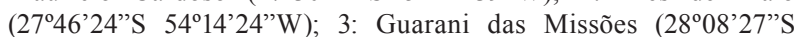

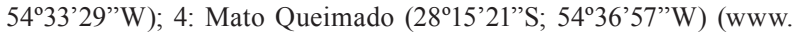
ibge.gov.br/mapas_ibge/pol.php).

We selected two populations of T. infestans from the Brazilian states of Minas Gerais (MG) (Montes Claros) and Goiás (GO) and maintained them in the laboratory for more than 10 generations as susceptibility reference strains. Insects from the municipality of Yacuiba, Bolivia, were used as a resistant reference strain since pyrethroid resistance has already been described for this region (Toloza et al. 2008)

Bioassays consisted of the application of $0.5 \mu \mathrm{L}$ deltamethrin solution to the dorsal regions of fasted firstinstar nymphs, aged five days, using a Hamilton microsyringe with a 50-repetition dispenser. WHO protocol (WHO 1994) suggests the use of $0.2 \mu \mathrm{L}$ of solution, but a larger volume was applied in the present protocol to avoid concentration changes due to evaporation. Deltamethrin (99.7\% purity; Bayer) was diluted into serial concentra- tions (from $0.02 \mathrm{ng} / \mu \mathrm{L}-4.0 \mathrm{ng} / \mu \mathrm{L}$ for RS and susceptible samples and from $2.0 \mathrm{ng} / \mu \mathrm{L}-640.0 \mathrm{ng} / \mu \mathrm{L}$ for resistant samples) that were used to produce mortality curves for each sample. A control group was set up for each sample and treated with acetone only. Thirty nymphs were used for bioassays of each insecticide concentration.

After application of the insecticide, treated nymphs were maintained under controlled conditions of temperature $\left(24^{\circ} \mathrm{C} \pm 2^{\circ} \mathrm{C}\right)$ and relative humidity $(75 \% \pm 5 \%)$. Mortality of the nymphs was evaluated $72 \mathrm{~h}$ after application of the insecticide. Based on their locomotory capacity, nymphs were characterised as normal (without alterations), intoxicated (with slight alterations) or knocked down (with marked alterations or immobile).

Mortality data from the bioassays were subjected to probit analysis to calculate the $50 \%$ and $99 \%$ lethal doses $\left(\mathrm{LD}_{50}\right.$ and $\left.\mathrm{LD}_{99}\right)$ and the slope of the straight line in the graph (which indicates homogeneity of the population) for triatomine samples from each locality or strain was evaluated. All normal nymphs were grouped as alive, while intoxicated and knocked-down specimens were classified as dead. The Probit Analysis programme (Raymond 1985) was used at this stage of the study. The $\mathrm{LD}_{50}$ and $\mathrm{LD}_{99}$ values were subsequently tabulated and the RRs for both lethal doses were calculated from the ratios of LDs in field and laboratory strain samples (RR $=$ LDfield $/$ LDlaboratory).

Laboratory strains from MG and GO were selected as deltamethrin susceptibility references since they had already passed through more than 10 generations free of contact with any insecticide, the criterion for susceptibility defined by the WHO (1994). The $\mathrm{LD}_{50}$ of the MG strain was the lower of the two, at $0.36 \mathrm{ng} / \mathrm{nymph}$, and it was thus selected for calculating the RR values of the other samples. The $\mathrm{LD}_{99}$ of this strain was $2.68 \mathrm{ng} /$ nymph and the slope 2.09 (Table I). The GO strain presented an $\mathrm{LD}_{50}$ value of $0.42 \mathrm{ng} / \mathrm{nymph}, \mathrm{LD}_{99}$ of $3.33 \mathrm{ng} /$ nymph and slope of 2.68. The RRs of this strain for $\mathrm{LD}_{50}$ and $\mathrm{LD}_{99}$ were 1.17 and 1.24 , respectively. No locomotory changes were noted in the control groups.

The $\mathrm{LD}_{50}$ values of the $\mathrm{RS}$ samples ranged from 0.26-0.67 ng/nymph, the $\mathrm{LD}_{99}$ values from $3.42-4.90 \mathrm{ng} /$ nymph and the slopes from 1.35-1.99 (Table I). Based on

TABLE I

$\mathrm{LD}_{50}, \mathrm{LD}_{99}$ and slope of Triatoma infestans samples and strains

\begin{tabular}{lccccccrrr}
\hline Localities & $\mathrm{LD}_{50}$ & \multicolumn{2}{c}{ CL 95\% } & LD $_{99}$ & \multicolumn{2}{c}{ CL 95\% } & & Slope & CL 95\% \\
\hline Montes Claros & 0.36 & 0.241 & 0.410 & 2.68 & 2.050 & 3.699 & 2.09 & \pm 0.33 \\
Goiás & 0.42 & 0.321 & 0.515 & 3.33 & 2.872 & 4.263 & 2.68 & \pm 0.47 \\
Mato Queimado & 0.53 & 0.354 & 0.710 & 3.42 & 2.766 & 5.778 & 1.80 & \pm 0.38 \\
Guarani das Missões & 0.35 & 0.240 & 0.548 & 4.00 & 3.511 & 4.982 & 1.35 & \pm 0.22 \\
Três de Maio & 0.67 & 0.520 & 0.925 & 4.90 & 4.201 & 6.025 & 1.99 & \pm 0.31 \\
Doutor Maurício Cardoso & 0.26 & 0.199 & 0.356 & 4.21 & 3.877 & 4.866 & 1.93 & \pm 0.28 \\
Yacuiba & 10.84 & 7.706 & 14.635 & 366.62 & 182.645 & 1.128 .377 & 1.52 & \pm 0.19 \\
\hline
\end{tabular}

Lethal doses (LD) correspond to amounts of deltamethrin/treated nymph (ng/tn). 


\section{TABLE II}

Resistance ratios (RR) of the lethal doses (LD) of Triatoma infestans samples and strains

\begin{tabular}{lll}
\hline Localities & $\mathrm{RR}\left(\mathrm{LD}_{50}\right)$ & $\mathrm{RR}\left(\mathrm{LD}_{99}\right)$ \\
\hline Goiás & 1.17 & 1.24 \\
Mato Queimado & 1.47 & 1.28 \\
Guarani das Missões & 0.97 & 1.49 \\
Três de Maio & 1.86 & 1.83 \\
Doutor Maurício Cardoso & 0.72 & 1.57 \\
Yacuiba & 30.11 & 136.80 \\
\hline
\end{tabular}

the LD values, it was possible to calculate the RRs for these samples; those for the $\mathrm{LD}_{50}$ ranged from 0.72-1.86 and those for the $\mathrm{LD}_{99}$ ranged from 1.28-1.83 (Table II).

According to the WHO (1994), RR values $<5$ indicate susceptibility. Thus, the RS samples of T. infestans studied here can be classified as highly susceptible to deltamethrin, contrary to expectations. Although these findings are very important from the point of view of vector control, it should not be forgotten that they are only valid for the samples studied here and cannot be extrapolated to other localities or populations of this species.

As shown in Table II, the RR values for Yacuiba confirm that this Bolivian sample is resistant to deltamethrin, as described elsewhere (Orihuela et al. 2008, Toloza et al. 2008). Deltamethrin resistance varies widely in Bolivia, where values for the RR of the $\mathrm{LD}_{50}$ in T. infestans range from 17.38 (Mataral) to 154.4 (Yacuiba). The difference between the present results and those previously published is likely due to methodological differences (the use of $0.5 \mu \mathrm{L}$ of insecticide solution instead of $0.2 \mu \mathrm{L}$ ). Nevertheless, as the RR is a ratio between two values, the proportions were maintained. Thus, the values in the present study for Yacuiba suggest that the phenomenon of insecticide resistance does not extend homogeneously over wide areas and may assume localised characteristics.

The RS populations studied here probably originated from different localities than those investigated by Vassena et al. (2000), which would explain the discrepancies between the results of the two studies. On the other hand, the resistance of these populations could also have been eliminated over the years that separated the two sampling periods. From our results, and taking into account the proximity of RS to the resistant populations in Argentina and Bolivia, we conclude that monitoring of these residual populations as a strategic control measure is fundamental, as was proposed by Rocha and Silva
(1979) without ever having been implemented. The persistence of $T$. infestans under the RS control programme may be due to environmental conditions like those observed in La Rioja, Argentina (Porcasi et al. 2007), indicating a need for the implementation of complementary tools, such as peridomicile reorganisation and elimination of vectorial refuges.

\section{ACKNOWLEDGEMENTS}

To Celia Lammerhirt, Secretary of Health of RS, for providing Triatoma infestans captured in that state, and Bayer CropScience, for providing the deltamethrin insecticide used in the bioassays.

\section{REFERENCES}

Dias E, Pellegrino J 1948. Alguns ensaios com o gammexane no combate aos transmissores da doença de Chagas. Brasil Med 62: 185-191.

Dias JC 2002. O controle da doença de Chagas no Brasil. In AC Silveira, O controle da doença de Chagas nos países do Cone Sul da América: uma iniciativa internacional. 1991/2001, Organização Pan-Americana da Saúde/Faculdade de Medicina do Triângulo Mineiro, Uberaba, p. 145-237.

Dias JC, Silveira AC, Schofield CJ 2002. The impact of Chagas disease control in Latin America: A review. Mem Inst Oswaldo Cruz 97: 603-612.

Diotaiuti L, Ribeiro de Paula O, Falcão PL, Dias JC 1994. Evaluation of the Chagas disease vector control program in Minas Gerais, Brazil, with special reference to Triatoma sordida. Bull Pan Am Health Organ 28: 211-219.

Orihuela PLS, Vassena CV, Zerba EN, Picollo MI 2008. Relative contribution of monooxygenase and esterase to pyrethroid resistance in Triatoma infestans (Hemiptera: Reduviidae) from Argentina and Bolivia. J Med Entomol 45: 298-306.

Porcasi X, Hrellac H, Catalá S, Moreno M, Abrahan L, Hernandez L, Gorla DE 2007. Infestation of rural houses by Triatoma infestans in the regions of Los Llanos (La Rioja, Argentina). Mem Inst Oswaldo Cruz 102: 63-68.

Raymond M 1985. Preséntation d'um programme d'analyse Log-Probit pour micro-ordinnateur. Ser Ent Met Parasitol 22: 117-121.

Rocha e Silva EO 1979. Profilaxia. In Z Brener, Z Andrade, Trypanosoma cruzi e doença de Chagas, Guanabara Koogan, Rio de Janeiro, p. 425-449.

Toloza AC, Germano M, Mougabure Cueto G, Vassena CV, Zerba E, Picollo MI 2008. Differential patterns of insecticide resistance in eggs and first instars of Triatoma infestans (Hemiptera: Reduviidae) from Argentina and Bolivia. J Med Entomol 45: 421-426.

Vassena CV, Picollo MI, Zerba EN 2000. Insecticide resistance in Brazilian Triatoma infestans and Venezuelan Rhodnius prolixus. Med Vet Entomol 14: 51-55.

Vinhaes MC, Dias JCP 2000. Chagas disease in Brazil. Cad Saude Publica 16 (Suppl. 2): 7-12.

WHO 1994. Protocolo de evaluación de efecto insecticida sobre triatominos. Acta Toxicol Argentina 2: 29-32. 